\title{
Thermal FAult Detection SySTEM FOR PV SOLAR MODULES
}

\author{
Atıl Emre Coşgun ${ }^{1}$ and Yunus Uzun ${ }^{2}$ \\ ${ }^{1}$ Department of Mechatronics, Aksaray University, Aksaray, Turkey \\ ${ }^{2}$ Department of Electrical and Electronics Eng., Aksaray University, Aksaray, Turkey
}

\begin{abstract}
Photovoltaic $(P V)$ modules used to convert sunlight into electricity. $P V$ researches and industries are rapidly becoming popular in the energy field since $P V$ technologies do not harm to environment and use sun which is unlimited energy source. Nowadays, many applications are realized with photovoltaic (PV) modules in different areas such as buildings, aviation, solar power plants, land and sea transportations, etc. Construction, operation and maintenance of solar PV system are not easy and complex. There are many methods for PV plants inspection such as visual inspection, using current sensors, comparing the input and output power units of PV modules, and thermal monitoring with infrared cameras. Monitoring the differences on the PV module output voltage by means of sensors is the most appropriate methods but it is very expensive solution since there are thousand $P V$ modules in some plants. Thermal monitoring system is more suitable method for large PV plants' inspection. Because, it reduces the fault detection costs and provide shorten maintenance time. The main aim of this paper is to investigate thermal monitoring of the $P V$ solar modules and realize image processing by thermal radiation on PV modules. For this purpose, it is created a wireless directable robotic vehicle which has RF and thermal camera, two brushless hub motor and $X$-Bee modules to send direction commands. In this way, the robot moves between the panels and sent data for user whether there is fault on the panels or not. The test results indicate that PV module faults are detected effectively by using thermal cameras.
\end{abstract}

\section{KEYWORDS}

Infrared, Thermal Monitoring, Photovoltaic (PV) Solar System, Fault Detection

\section{INTRODUCTION}

Recently, there is an increasing interest for solar energy systems [1,2] because they have some advantages such as being harmless for the environment, unlimited and renewable [3]. Solar photovoltaic system is an important energy system which converts sunlight into electricity with PV modules. The obtained electrical energy is stored or used directly, fed back into grid line or combined with other renewable energy source. Generally there are two type photovoltaic systems. They are classified depend on their operational and functional needs, component requirements, and how the energy is transferred other electrical loads and electrical sources. These are gridconnected or utility-interactive systems and stand-alone systems. By means of stand-alone PV systems are provided to operate as independently. Their electric utility grids are designed and sized to certain DC and/or AC levels. Grid-connected or utility-interactive PV systems are realized as parallel to electric utility grids and operated. The main component of it is the inverter or power conditioning unit (PCU). Its working principle is like that, when electric is produced by the PV array as DC power, it converts into AC power consistent with the power quality needs of the utility grid. Also there is another task of it, when the utility grid is not energized, automatically stops supplying power to the grid. Solar PV systems are not harmful to the nature, it is quite reliable and clean source of electricity when the compared other electricity produced

DOI: 10.14810/elelij.2017.6302 
methods. Therefore, there are many application examples such as agriculture, industry, residence, livestock, etc. The number of PV plants is rapidly increased almost everywhere. In the energy field European countries has a lot of experience. Although their experiences photovoltaic (PV) field is particularly, renewable energy sources (RES) field is generally and both of them experiences, increased a lot [4].

There are six parts in solar photovoltaic system. They are PV module, solar charge controller, inverter, battery bank, auxiliary energy sources and loads (appliances).

- PV module supply electricity to the system.

- Solar charge controller regulates the voltage and current levels and it supply energy to the battery. In this way prevents battery overcharging and prolongs the battery life.

- Inverter converts DC power into AC power.

- Battery used to supply power when demand an electric.

- Load is an electrical appliance that is connected to solar PV system such as laptop, washing machine, $\mathrm{TV}$, etc.

- Auxiliary energy sources are diesel generator or other renewable energy sources.

Despite developments in the photovoltaic technology, efficiency of commercially available PV cells is generally around 15\%-19\% [5]. Maintenance of the PV system is a crucial factor for efficiency. The traditional visual inspection is depending on human capabilities. This responsibility could be sometimes boring and not reliable. Also it takes long time to detect failure. In addition to, this system is not able to provide online information about failure therefore an extra required analysis time for it. On the contrary, the UAVs can carry out the fault detection of panels in shorter time because of their high speed and flexibility [4]. There is made a study about PV panel situation observation from air using IR and visual cameras. Mohammadreza et al. realized this application with success [6]. The main purpose of our study is to investigate PV module performance and achieve rapid image by means of infrared camera. For this purpose a low cost PV panel setup in laboratory and created a computer interface $(\mathrm{C}$ based) software with MATLAB in order to processing the received image from the thermal cameras. And for this purpose, it is created a wireless directable robotic vehicle which has RF and thermal camera, two brushless hub motor and X-Bee modules to send direction commands.

\section{EXPERIMENTAL SETUP AND METHODOLOGY}

\subsection{Test platform}

Test platform consist of a $40 \mathrm{~W}$ PV panel and measurement units. It is shown in Figure 1. As the measurement units a multimeter and an infrared camera are used. The infrared camera is Optris Pi 160 that has measurement speed of $120 \mathrm{~Hz}$ and has $160 \times 120$ pixel optic resolutions. 
Electrical and Electronics Engineering: An International Journal (ELELIJ) Vol.6, No.3, August 2017

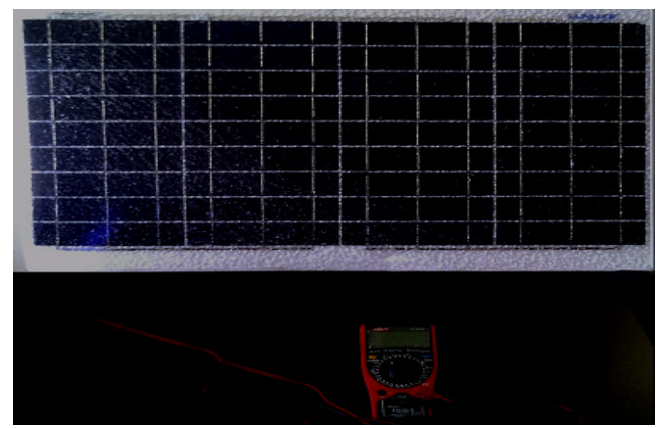

Figure 1. PV panel and multimeter

There is two meters between the infrared camera and PV panel. The panel set to about 90 degree against the camera. It is shown block diagram of test platform in Figure 2. The PV panel electrical characteristics are given in Table 1.

Table 1. The elecrical charasteristics of PV panel

\begin{tabular}{|c|c|}
\hline Open circuit voltage - Voc & $24 \mathrm{~V}$ \\
\hline Optimum operating voltage - Vmp & $21 \mathrm{~V}$ \\
\hline Short circuit current - Isc & $1.7 \mathrm{~A}$ \\
\hline Optimum operating current - Imp & $1.3 \mathrm{~A}$ \\
\hline Operating temperature & -40 to $85^{\circ} \mathrm{C}$ \\
\hline
\end{tabular}

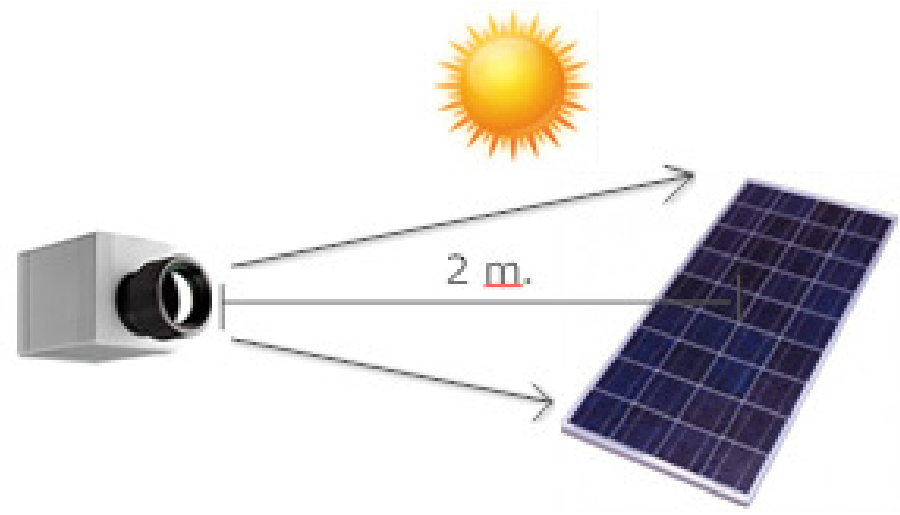

Figure 2. Block diagram of test platform

\subsection{Methodology}

In this study, after the setting test platform, there are five different images were taken from the PV panel by the help of the camera at regular intervals. They are used as reference images. After the five images, at the PV panel parallel cells solders connection was broken. It is shown in Figure 3 and then again an image was captured from the panel As a result of the broken parallel cells solders connections, the panel's power decrease from $40 \mathrm{~W}$ to $33 \mathrm{~W}$. Performance of the panel decrease $17.5 \%$. 
The images were evaluated by the help of MATLAB software. They were read into the MATLAB environment using function imread. According to developed $\mathrm{C}$ based algorithm, faulty image is obtained. It is a kind of image contours methods because program is automatically display a contour plot of the data in an intensity image.

\section{TEST RESUlt AND DisCUSSION}

To detect the broken cells effect on PV panel has taken sample image on panel with periodic time intervals. Measurements are obtained from PV panel are given in Table 2. From Table 2, a small voltage changing can be seen in the fifth row respect to sixth row. The reason of this situation is broken solder connections. There is a linear increase between the PV panel output voltages. In generally, there are almost 15 minute intervals for the panel output voltage measurements. But sixth row has taken measurement about 45 minutes later respect to other measurements. According to linear interpolation calculations the output voltage of sixth row must be $11.4 \mathrm{~V}$ but it is $10.9 \mathrm{~V}$. It is shows that the broken solder connection is the cause of the voltage drops.

Table 2. PV panel measurement data

\begin{tabular}{|c|c|c|c|}
\hline Test No & Temperature $\left({ }^{\circ} \mathbf{C}\right)$ & Output Voltage(V) & Time(s) \\
\hline 1 & 28.1 & 9.47 & $12: 17$ \\
\hline 2 & 28.7 & 10.04 & $12: 31$ \\
\hline 3 & 29.2 & 10.16 & $12: 46$ \\
\hline 4 & 29.8 & 10.24 & $13: 02$ \\
\hline 5 & 30.3 & 10.58 & $13: 18$ \\
\hline 6 & 29.9 & 10.9 & $14: 03$ \\
\hline
\end{tabular}

PV panel output voltage value varies depending on ambient temperature changes and brightness. In the Figure 3, "II" column is gray state of samples. They are turned into gray by means of Pi Connect software. In the Figure 3, column "I" $a, b, c, d$ and $e$ are infrared images.

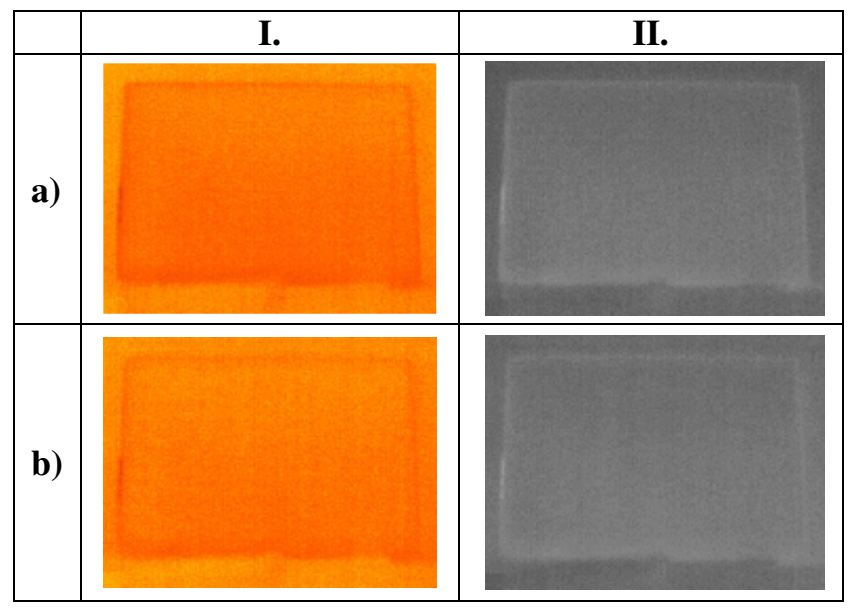


Electrical and Electronics Engineering: An International Journal (ELELIJ) Vol.6, No.3, August 2017

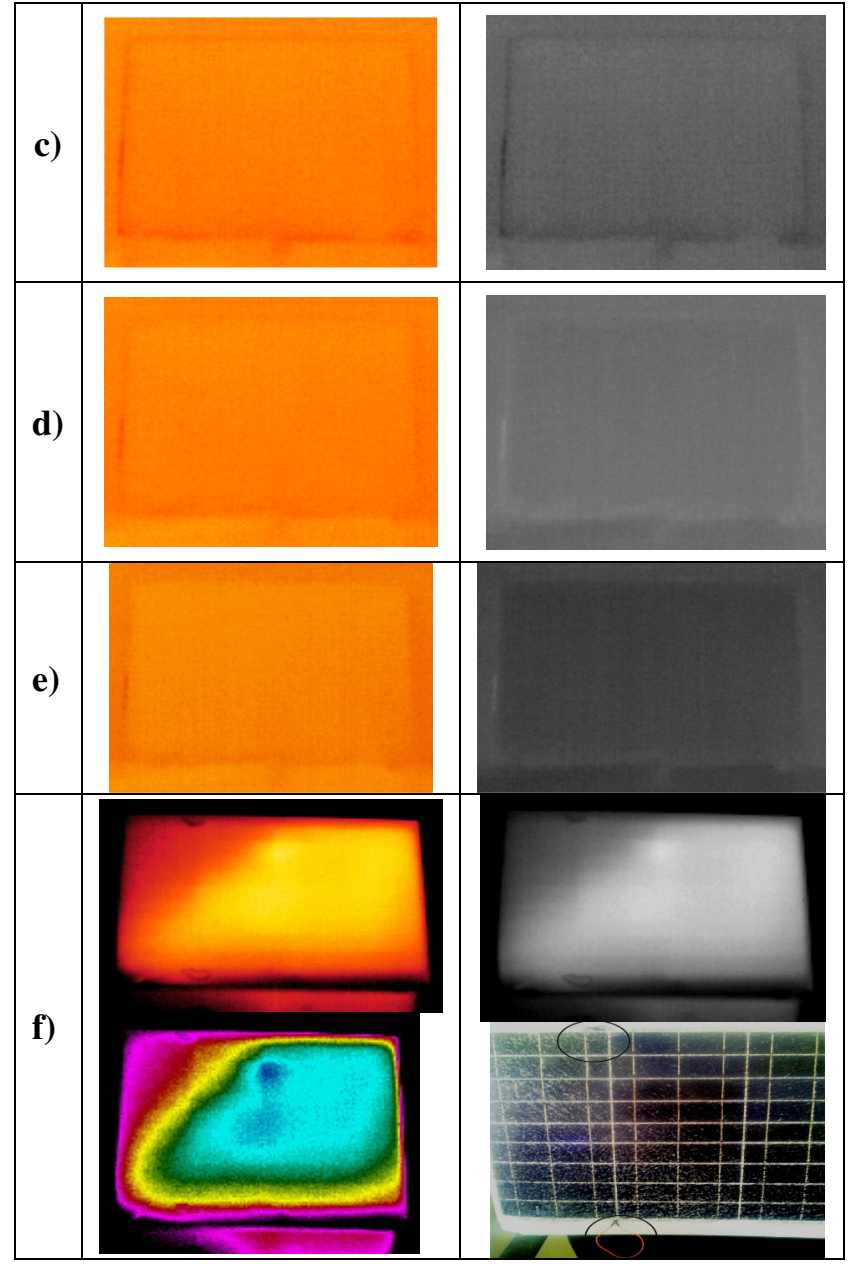

Figure 3. PV panel sample images

All of them are obtained from properly working PV panel but $f$ is obtained from broken solder connection cell on the panel. It is shown in Figure 4. Properly works cells' shape like a rectangular, but the shape of broken cells is different from the other.

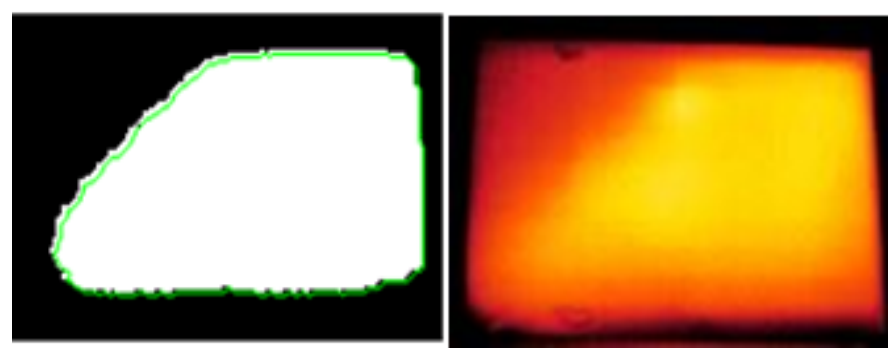

Figure 4. Image processing with MATLAB

In this study, it is clearly seen that linearly result is obtained from properly working PV panel cells. It is shown in Figure 5. 
Electrical and Electronics Engineering: An International Journal (ELELIJ) Vol.6, No.3, August 2017

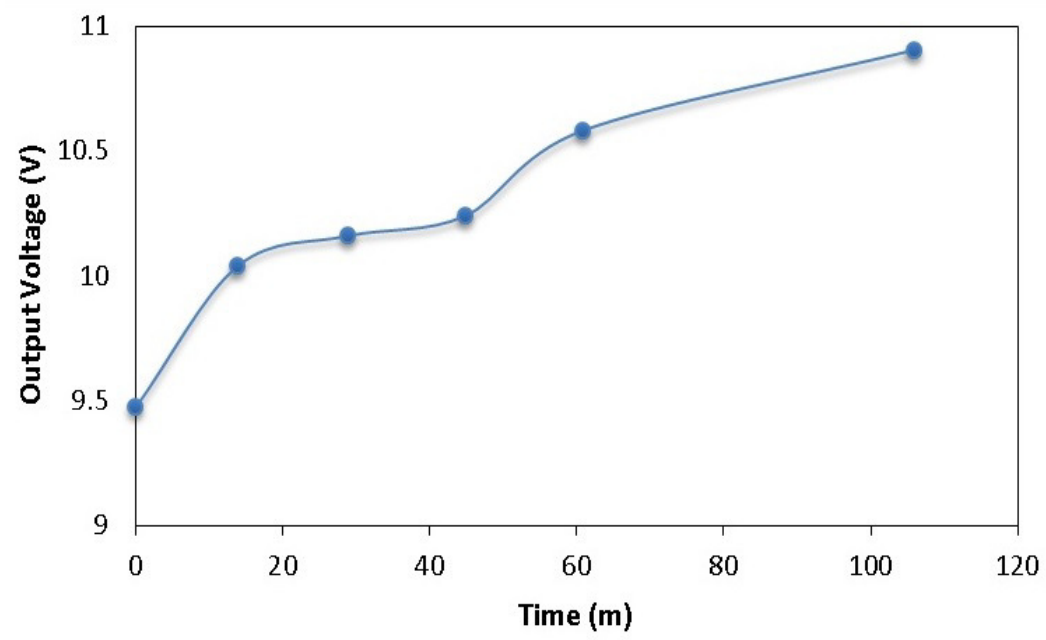

Figure 5. PV panel output voltage depends on the time

The PV panel output voltage is changing with time depends on the sun brightness. In the Figure 5, the output voltages of the panel are almost half of total capacity of it. All measurements are taken the initiation of experiment. Depending on the PV panel characteristic, efficiency is decreasing with the high temperatures so their optimal working temperature is very important to get proper data.

\section{Conclusions}

Solar energy systems are rapidly becoming popular among the renewable systems. Therefore the electrical energy can be generated using PV modules in the suitable places. In this point, the trouble-free work of PV panels is very important. The proposed study shows solder connection has an important effect on efficiency of PV panel output and the situation of PV panels can be observed with infrared cameras using appropriate systems. The faults of PV panels detected with high accuracy. Thermal monitoring system is more suitable method for the fault detection of the large PV plants in terms of low costs and short maintenance time. As a result of this study, fault detection of PV panel with infrared cameras is very fast, economics method and this method provide more accurate data when compared to the traditional methods. In the future works, we will plan to investigate that observation image of panel by unmanned aerial vehicle (UAV). The UAV will send optics and thermal images to ground control station for obtain accurate data about PV panel.

\section{REFERENCES}

[1] E. Reiter, K. Ardani, R. Margolis, R. Edge, (2015) "Industry perspectives on advanced inverters for us solar photovoltaic systems: Grid benefits, deployment challenges, and emerging solutions", NREL Tech. Rep., No. NREL/TP-7A40-65063.

[2] Y. Yang, P. Enjeti, F. Blaabjerg, H. Wang, (2015) "Wide-scale adoption of photovoltaic energy: Grid code modifications are explored in the distribution grid", IEEE Industry Applications Magazine, Vol. 21, No. 5, pp 21-31.

[3] G. Velasco-Quesada, F. Guinjoan-Gispert, R. Pique-Lopez, M. Roman-Lumbreras, A. Conesa-Roca, (2009) "Electrical PV Array Reconfiguration Strategy for Energy Extraction Improvement in GridConnected PV Systems", IEEE Transactions on Industrial Electronics, Vol. 56, No. 11, pp4319-4331. 
Electrical and Electronics Engineering: An International Journal (ELELIJ) Vol.6, No.3, August 2017

[4] F. Grimaccia, M. Aghaei, M. Mussetta, S. Leva, P. B. Quater, (2015) "Planning for PV plant performance monitoring by means of unmanned aerial systems (UAS)", International Journal of Energy and Environmental Engineering, Vol. 6, No. pp47-54.

[5] B. Huang, Y. Huang, G. Chen, P. Hsu, K. Li, (2013) "Improving Solar PV System Efficiency Using One-Axis 3-Position Sun Tracking,” Energy Procedia, Vol. 33, pp280-287.

[6] A. Mohammadreza, G. Francesco, A. Carlo Gonano, L. Sonia, (2015) "Innovative automated control system for PV fields inspection and remote control", IEEE Transactions on Industrial Electronics, Vol. 62, No. 11, pp7287-7296.

\section{AUTHORS}

Atıl Emre Cosgun received the Master degree in Mechatronics field from the University of Karabuk, Turkey, in 2014. From 2015 to 2017 has been continued Ph.D. in Electrical and Electronics Engineering Department from University of Aksaray. Since 2016, he is an instructor in the Aksaray University. His research interests are robot control and UAV systems.

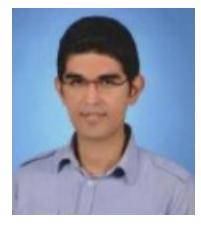

Yunus Uzun received his B.S., M.Sc. and Ph.D. degrees from the Gazi University in 2000, 2004 and 2012, respectively. He worked as a high school teacher on electrics from his graduation to 2008. He was a lecturer in the Department of Electrics and Energy of Ahi Evran University for 6 years. Then he was assigned to the Assist. Prof. Dr. position in Dept. Electrical and Electronics Engineering of Aksaray University in 2014. His main research area focuses on the experimental and theoretical explorations of energy harvesting

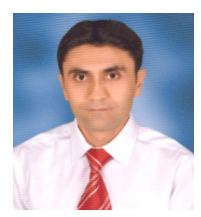
systems. 
Electrical and Electronics Engineering: An International Journal (ELELIJ) Vol.6, No.3, August 2017

INTENTIONAL BLANK 